\title{
Inhibition of Bone Resorption In Vitro by Antisense RNA and DNA Molecules Targeted against Carbonic Anhydrase II or Two Subunits of Vacuolar $\mathrm{H}^{+}$-ATPase
}

Tiina Laitala and H. Kalervo Väänänen

Department of Anatomy, University of Oulu, Kajaanintie 52 A, FIN-90220 Oulu, Finland

\begin{abstract}
The bone resorbing cells, osteoclasts, express high levels of carbonic anhydrase II (CA II) and vacuolar $\mathrm{H}^{+}$-ATPase (VATPase) during bone resorption. We have used antisense RNA and DNA molecules targeted against CA II, and against 16- and 60-kD subunits of vacuolar $\mathrm{H}^{+}$-ATPase (V-ATPase), to block the expression of these proteins in vitro. Osteoclastic bone resorption was studied in two in vitro culture systems: release of ${ }^{45}$ Calcium from prelabeled newborn mouse calvaria cultures, and resorption pit assays performed with rat osteoclasts cultured on bovine bone slices. Both antisense RNA and DNA against CA II and the V-ATPase were used to compare their specificities as regards inhibiting bone resorption in vitro. The antisense molecules inhibited the synthesis of these proteins by decreasing the amounts of mRNA in the cells in a highly specific manner. In osteoclast cultures treated with the 16-kD VATPase antisense RNA, acidification of an unknown population of intracellular vesicles was highly stimulated. The acidification of these vesicles was not sensitive to amiloride or bafilomycin $A_{1}$. This suggests the existence of a back-up system for acidification of intracellular vesicles, when the expression of the V-ATPase is blocked. Our results further indicate that blocking the expression of CA II and V-ATPase with antisense RNA or DNA leads to decreased bone resorption. ( $J$. Clin. Invest. 1994. 93:2311-2318.) Key words: antisense RNA/DNA • osteoclast • vacuolar $\mathrm{H}^{+}$-ATPase • carbonic anhydrase II • bone resorption
\end{abstract}

\section{Introduction}

Osteoclastic bone resorption is a multistep process in which osteoclast precursors are activated to form mature osteoclasts. The osteoclast is a rapidly moving cell which cycles between resorptive and nonresorptive phases (1). Osteoclasts resorb inorganic bone matrix by producing acid: a vacuolar $\mathrm{H}^{+}$-ATPase (V-ATPase $)^{1}$ pumps protons into resorption lacunae, where a low $\mathrm{pH}$ is required for mineral dissolution $(2,3)$. In the cytoplasm of osteoclasts, carbonic anhydrase II (CA II) generates

Address correspondence to Tiina Laitala, Department of Anatomy, University of Oulu, Kajaanintie 52 A, FIN-90220 Oulu, Finland.

Received for publication 12 July 1993 and in revised form 22 February 1994.

1. Abbreviations used in this paper: AO, acridine orange; CA II, carbonic anhydrase II; cRT-PCR, competitive RT-PCR; RT-PCR, reverse transcription PCR; V-ATPase, vacuolar $\mathrm{H}^{+}$-ATPase; VSV, vesicular stomatitis virus.

J. Clin. Invest.

(C) The American Society for Clinical Investigation, Inc.

$0021-9738 / 94 / 06 / 2311 / 08 \quad \$ 2.00$

Volume 93, June 1994, 2311-2318 protons for the vacuolar proton pump (4-6). The expression of these enzymes is dependent on the resorptive phase of the osteoclast (7). In resorbing osteoclasts, both CA II and V-ATPase are highly expressed, whereas in nonresorbing osteoclasts only a low basal expression is maintained.

Antisense RNA and DNA molecules inhibit the translation of specific proteins in vitro and in vivo. These molecules are capable of entering living cells and hybridizing to their target mRNA. This most probably results in degradation of the mRNA by RNAse $\mathrm{H}$, and thus inhibition of protein synthesis (8). Up to $95 \%$ inhibition of protein synthesis has been reported. The mechanism for uptake of short or long nucleic acids in eukaryotic cells is unknown. An $80-\mathrm{kD}$ membrane protein has been suggested to be involved in oligonucleotide transport into cells by a mechanism resembling receptor-mediated endocytosis (9). Short antisense DNA-oligos have been used to inhibit DNA synthesis and mitosis (10), as well as cell proliferation (11). Antisense RNA molecules have also been used in similar studies, even though the half-life of exogenous RNA is probably very short (12-15).

Earlier studies have shown that enzyme inhibitors against carbonic anhydrases and V-ATPase can be used to inhibit bone resorption $(6,16,17)$. Antisense mRNA against the catalytic 70-kD subunit of V-ATPase has been used to inhibit carrot tonoplast $\mathrm{H}^{+}$-ATPase in vivo (18). In this investigation we studied the roles of V-ATPase and CA II on osteoclastic bone resorption in vitro, using antisense technology. Expression of CA II and the 16- and $60-\mathrm{kD}$ subunits of V-ATPase was blocked by antisense RNA and DNA. The V-ATPase subunits were chosen on the basis of their vital role for the function of the enzyme (19). Short 18-nt DNA-fragments, and up to 1,100-nt RNA-fragments were used to study their usefulness, effects and specificity in the inhibition of bone resorption in vitro. The effects of antisense molecules on resorption activity and protein synthesis, as well as on acidification of intracellular vesicles, were studied in cultured rat osteoclasts and mouse calvaria.

\section{Methods}

The cDNAs coding for the bovine 16-kD V-ATPase subunit (obtained from Dr. Nelson, Roche Institute, Nutley, NJ) (20) and mouse CA II (obtained from Dr. Curtis, Wistar Institute, Philadelphia, PA) (21) were subcloned into pGEM-3Z (Promega, Madison, WI) using standard procedures $(22,23)$. For in vitro transcription, the plasmids containing the cDNA were digested to obtain linear templates. All restriction enzymes were purchased from Boehringer Mannheim GmbH (Mannheim, Germany) and other DNA-modifying enzymes from Promega. In vitro transcription was performed using T7 and SP6 RNA polymerase according to Promega's instructions, and antisense or sense RNA-molecules were used at a concentration of $1 \mu \mathrm{g} / \mathrm{ml}$. rRNAsin (Promega) at $50 \mathrm{U} / \mathrm{ml}$ was added to the culture medium $15 \mathrm{~min}$ before adding the RNA, to inactivate RNAse activity in the medium. In all 
experiments, samples with no nucleotide addition were used as controls. $\lambda$-DNA digested with EcoRI was used as an extra non-sense control in all experiments. Statistical significances were determined by variance analysis and Student's $t$ test using Bonferroni's adjustment.

The homology between 16- and 60-kD V-ATPase subunits from different sources is very high, and oligonucleotides were chosen from areas with $100 \%$ interspecies homology. Normal and phosphorothioate (S)-DNA-oligonucleotides (24) were synthesized by use of an Applied Biosystems DNA-synthesizer (Applied Biosystems, Inc., Foster City, CA). After synthesis, the oligonucleotides were detached from the column with $25 \%$ ammonia solution $\left(+55^{\circ} \mathrm{C}\right.$ overnight), vacuum dried, and dissolved in water. Oligonucleotides were purified by PAGE electrophoresis following ethanol precipitation, and dissolved again in water. The oligonucleotides were used at a concentration of $1 \mu \mathrm{g} / \mathrm{ml}$.

For the in vitro resorption pit assay, 2-3-d-old Sprague-Dawley rat osteoclasts were cultured on bovine cortical bone slices as previously described (25). Antisense or sense RNA/DNA was added to the culture medium, and cells were cultured for $24 \mathrm{~h}\left(+37^{\circ} \mathrm{C}, 5 \% \mathrm{CO}_{2}\right)$. To determine the resorption activity, cells were fixed with $3 \%$ paraformaldehyde $+0.2 \%$ saccharose and stained with $1 \%$ toluidine blue $+1 \%$ sodium borate. Cells with at least three nuclei were counted as osteoclasts. After this, the bone slices were brushed free of cells and the resorption lacunae stained with wheat germ agglutinin-lectin (Sigma Chemical Co., St. Louis, MO). Bone slices were incubated for $20 \mathrm{~min}$ in peroxidase-conjugated WGA-lectin $(20 \mu \mathrm{g} / \mathrm{ml})$, washed with PBS, and incubated for $15 \mathrm{~min}$ in diaminobenzidine $(0.5 \mathrm{mg} / \mathrm{ml})+0.03 \%$ $\mathrm{H}_{2} \mathrm{O}_{2}$. Morphometric analysis of the resorption pits was performed with an MCID-image analyzer utilizing M2-software (Imaging Research Inc., Brock University, Ontario, Canada).

The effects of antisense RNA and DNA on the corresponding mRNA and protein levels were studied by immunostaining, immunoprecipitation, and quantitative RT-PCR (CRT-PCR; 26, 27). For immunostaining of CA II in osteoclasts, rat osteoclasts were cultured in the presence of CA II antisense or sense RNA/DNA and fixed. CA II protein was detected using polyclonal CA II antibodies and rhodamineconjugated swine anti-rabbit immunoglobulins (DAKOPATTS A/S, Glostrup, Denmark) as previously described (6).

For CA II immunoprecipitation, rat osteoclasts were cultured with CA II antisense or sense RNA/DNA, and then transferred to labeling medium containing $50 \mu \mathrm{Ci}\left[{ }^{35} \mathrm{~S}\right.$ ] methionine. After $4 \mathrm{~h}$, the cells were washed three times, and disrupted by sonication ( $10 \mathrm{mM}$ Tris- $\mathrm{HCl}, \mathrm{pH}$ 7.5, $2 \mathrm{mM}$ EDTA, $10 \mathrm{mM} \mathrm{NaCl}, 0.5 \%$ Triton X-100, 0.3\% SDS, $50 \mu \mathrm{M}$ PMSF). Samples were taken for scintillation counting, and CA II protein was immunoprecipitated with polyclonal antibodies bound to protein A sepharose CL (Sigma Chemical Co.) (28). The immunoprecipitate was washed twice ( $50 \mathrm{mM}$ Tris- $\mathrm{HCl}, \mathrm{pH} 8.3,0.6 \mathrm{M} \mathrm{NaCl}, 1 \mathrm{nM}$ $\mathrm{N}$-octylglucoside), centrifuged and the final precipitate was dissolved in SDS-PAGE loading buffer. Samples for scintillation counting were taken, and counted. After electrophoresis, the $10 \%$ SDS-gel was fixed with $50 \%$ methanol $+12 \%$ acetic acid, immersed in $\mathrm{EN}^{3} \mathrm{HANCE}$ ( DuPont NEN, Boston, MA), dried, and subjected to autoradiography.

For cRT-PCR, a 40-nt MaeII-ApaLI fragment was removed from the bovine 16-kD V-ATPase cDNA, and a 120-nt NdeI-BgllI fragment from mouse CA II cDNA. The re-ligated cDNA's were used as templates for in vitro transcription, and the resulting RNA-molecules were used as internal standards in quantitative PCR (26). Total RNA was isolated from four bone slices containing the cultured osteoclasts (7). The procedure for CRT-PCR was as follows: $50 \mathrm{ng}$ of total RNA and 5 ng of standard RNA was mixed with 100 ng each of: RT-oligo ( 5 ' GACTCGAGTCGACATCGATTTTTTTTTTTTTTTTT3', reverse PCRoligo (5'GACTCGAGTCGACATCG3') and gene-specific forward PCR-oligo (for V-ATPase: 5'CATGTCCGAGGCCAAGA3' and for CA II: 5'ACCATGTCCCACCACTG3'). RT-PCR was performed as previously described (7). Samples were run in 3\% MetaPhor-agarose (FMC Corp., Rockland, ME) gels containing ethidium bromide ( 1 $\mu \mathrm{g} / \mathrm{ml})$.

The effects of antisense and sense RNA on acidification of intracellular vesicles were followed by acridine orange $(\mathrm{AO})$ uptake into living cells. Various enzyme inhibitors were added to the osteoclast culture media together with antisense or sense RNA at the beginning of the culture, to characterize the acidification system induced by A-16-RNA. $1 \mathrm{mM}$ amiloride was used to block the $\mathrm{Na}^{+} / \mathrm{H}^{+}$pump, and $0.1-10 \mathrm{nM}$ bafilomycin $A_{1}$ was used to block V-ATPases. Cells were incubated in $\mathrm{AO}$ at $5 \mu \mathrm{g} / \mathrm{ml}$ for $15 \mathrm{~min}$ at $37^{\circ} \mathrm{C}$, mounted in medium, and viewed under a microscope using a fluorescein filter.

To further study the acidification mechanism after A-16-RNA treatment, vesicular stomatitis virus (VSV) infection was used as a model for endosomal acidification. For these studies, osteoclasts were cultured for $24 \mathrm{~h}$ in the presence of antisense or sense RNA, or $10 \mathrm{nM}$ bafilomycin $A_{1}$. Two plaque-forming units of VSV were added to the culture medium, and after $4 \mathrm{~h}$ the cultures were fixed. VSV G-protein inside osteoclasts was visualized by use of a polyclonal antibody, as previously described (29).

For mouse calvarial cultures, 1-d-old NMRI-mice were injected

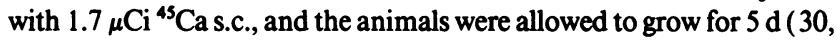
$31)$. The mice were sacrificed and calvaria dissected into culture medium (CMRL-1066, 0.1\% BSA, $50 \mu$ g gentamycin/ml, $100 \mathrm{U}$ penicillin, $100 \mu \mathrm{g}$ streptomycin/ml; GIBCO, Paisley, UK). Calvaria were preincubated for $1 \mathrm{~d}$ in CMRL-medium containing $0.5 \mu \mathrm{g}$ indomethacin/ml (Dumex, Denmark) and $10 \mathrm{nM}$ PTH (Sigma Chemical Co.). The calvaria were then cultured in CMRL-medium in the absence of indomethacin, and in the presence of PTH and antisense or sense nucleotides for an additional $3 \mathrm{~d}$. Antisense or sense RNA/DNA was added every day to keep its amount as constant as possible. To measure the liberated and bound radioactivity, calvaria were dissolved in $6 \mathrm{M}$ hydrocloric acid. Both the culture media and dissolved bone were counted in a scintillation counter.

Table I. Nucleotide Molecules and Their Abbreviations and Sequences

\begin{tabular}{|c|c|}
\hline Abbreviation & Sequence \\
\hline A-16-RNA & $\begin{array}{l}1100 \text {-nt antisense in vitro transcript from } \\
\text { bovine 16-kD V-ATPase subunit cDNA }\end{array}$ \\
\hline S-16-DNA & $\begin{array}{l}\text { 1100-nt sense in vitro transcript from bovine } \\
16-\mathrm{kD} \text { V-ATPase subunit cDNA }\end{array}$ \\
\hline A-16-DNA & $\begin{array}{l}\text { 18-mer antisense DNA oligonucleotide from } \\
\text { bovine 16-kD V-ATPase subunit cDNA: } \\
5^{\prime} \text { TTGGCCTCGGACATGTCT } 3^{\prime}\end{array}$ \\
\hline S-16-DNA & $\begin{array}{l}\text { 18-mer sense DNA oligonucleotide from bovine } \\
\text { 16-kD V-ATPase subunit cDNA: } \\
\text { 5' AGACATGTCCGAGGCCAA 3' }\end{array}$ \\
\hline A-60-DNA & $\begin{array}{l}\text { 18-mer antisense DNA oligonucleotide from } \\
\text { bovine } 60-\mathrm{kD} \text { V-ATPase subunit cDNA: } \\
5^{\prime} \text { TTCACGATCCCCCGCATC } 3^{\prime}\end{array}$ \\
\hline S-60-DNA & $\begin{array}{l}\text { 18-mer sense DNA oligonucleotide from bovine } \\
\text { 60-kD V-ATPase subunit cDNA: } \\
\text { 5' GATGCGGGGGATCGTGAA 3' }\end{array}$ \\
\hline A-CAII-RNA & $\begin{array}{l}\text { 450-nt antisense in vitro transcript from mouse } \\
\text { CAII cDNA }\end{array}$ \\
\hline S-CAII-RNA & $\begin{array}{l}\text { 450-nt sense in vitro transcript from mouse } \\
\text { CAII cDNA }\end{array}$ \\
\hline A-CAII-DNA & $\begin{array}{l}\text { 18-mer antisense DNA oligonucleotide from } \\
\text { mouse CAII cDNA: } \\
\text { 5' CCAGTGGTGGGACATGGT 3' }\end{array}$ \\
\hline S-CAII-DNA & $\begin{array}{l}\text { 18-mer sense DNA oligonucleotide from mouse } \\
\text { CAII cDNA: } \\
\text { 5' ACCATGTCCCACCACTGG } 3^{\prime}\end{array}$ \\
\hline
\end{tabular}




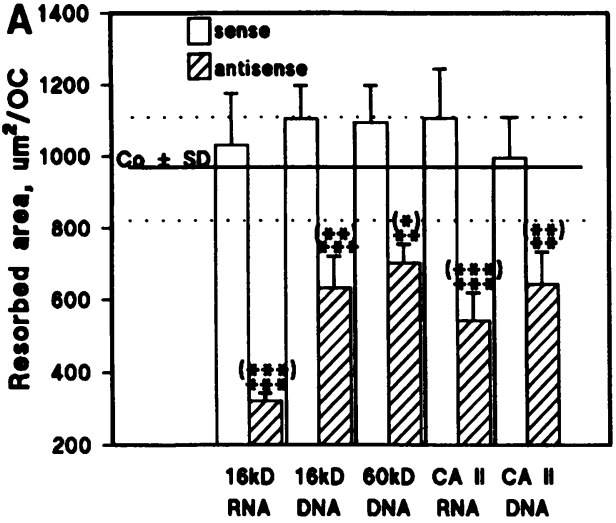

Nucloic acid

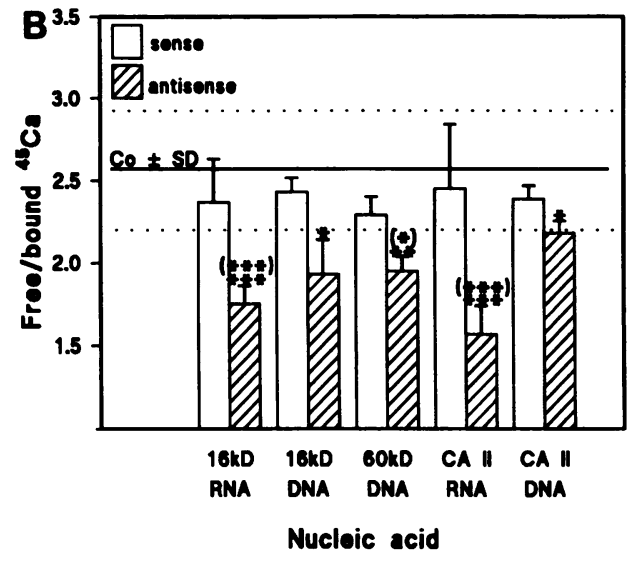

Figure 1. (A) Resorbed bone area per osteoclast $(O C)$ after antisense or sense RNA/DNA treatment \pm SD. Eight bone slices per sample $(6 \times 7 \mathrm{~mm})$, containing $\sim 200$ osteoclasts each, were studied. The $P$ values between sense and antisense, and control and antisense (in parenthesis) are shown as asterisks $\left({ }^{*} P<0.05 ;{ }^{* *} P<\right.$ $0.01 ; * * * P<0.001)$. (B) Bone resorption in mouse calvaria cultures treated with antisense or sense RNA/DNA \pm SD. The $P$ values between sense and antisense, and control and antisense (in parenthesis) are shown as asterisks $\left({ }^{*} P<0.05 ;{ }^{* *} P<0.01 ;{ }^{* * *} P<\right.$ $0.001 ; n=20)$.

\section{Results}

The RNA/DNA molecules used in this study are described in Table 1. Fig. $1 A$ shows the effects of the different antisense RNAs and DNAs on the total resorbed areas per osteoclast in the resorption pit assay. Significant decreases in the resorbed areas/OC were seen after treatment with the antisense fragments tested. A-16-DNA and A-CA II-DNA inhibited bone resorption by 43 and 35\%, respectively, compared with 69 and $51 \%$ inhibition obtained with the corresponding RNA fragments. The different sense DNAs, $\lambda$-DNA fragments, or rRNase-inhibitor alone had no effect on bone resorption, and the data were pooled with the controls. This experiment showed that either antisense RNA or DNA could be used to inhibit bone resorption. However, the RNA molecules appeared to be more potent inhibitors of bone resorption than than the DNA molecules.

In the mouse calvariae experiments, significant inhibition of bone resorption was also observed with the antisense RNAs / DNAs (Fig. $1 B$ ). The inhibitory effect of the antisense molecules varied between 9\% (A-CA II-DNA) and 36\% (A-CA IIRNA). The strongest inhibition was achieved in this model also with antisense RNA.

To check the effects of nuclease-resistant DNA oligonucleotides on bone resorption, we compared these S-DNA-oligos with the corresponding normal DNA oligonucleotides. The data presented in Table II show that the protected antisense DNA molecules had no better inhibitory effect on bone resorption than the normal antisense DNAs. On the basis of this, we used normal antisense DNA oligonucleotides in further experiments. The antisense DNAs inhibited bone resorption in vitro dose dependently. As can be seen from Fig. 2, as little as $0.1 \mu \mathrm{g}$ of antisense DNA $/ \mathrm{ml}$ inhibited bone resorption in the resorption pit assay, and the inhibitory effect increased when more antisense DNA was added.

To check for the ability of antisense molecules to block the synthesis of specific proteins, immunoprecipitation and cRTPCR were used. The staining pattern for CA II in osteoclasts is shown in Fig. 3. In Fig. 3, $A$ and $D$ represent the immunofluorescence staining of CA II protein; $B$ and $E$ represent nuclear staining of the same samples; and $C$ and $F$ represent bone surface under the cells. Fig. $3, A, B$, and $C$ are from the same site, and $D, E$, and $F$ represent the same site. CA II was highly expressed in the sense-treated, bone-resorbing osteoclasts (Fig. $3, A-C)$. In the antisense-treated cultures, $89 \%$ of the osteoclasts were negative for CA II (Fig. 3, $D$ and $E$ ). None of these CA II-negative osteoclasts were resorbing bone at the time of fixation, as determined by the intact bone surface under these cells (Fig. $3 F$ ). In these experiments, both A-CA II RNA and DNA appeared to have similar effects.

To determine translation activity in the antisense-treated cultures, metabolically labeled CA II protein was immunoprecipitated by CA II antibodies (Fig. $4 A$ ). These results showed that antisense RNA (Fig. $4 A$, lane 3 ) was somewhat more potent in inhibiting CA II synthesis than the corresponding DNA-oligo (Fig. $4 A$, lane 5 ). When samples were analyzed by scintillation counting after labeling and immunoprecipitation, we found no changes in the radioactivity of the samples after labeling ( $35800 \pm 2760 \mathrm{cpm}$ ). After immunoprecipitation, radioactivity of the control was $5923 \pm 443$, and $6689 \pm 330$ or $5276 \pm 212$ in the S-CA II-RNA and DNA, respectively. In the

Table II. Effects of S-modified and Normal DNA-oligos on Bone Resorption in the Resorption Pit Assay $(n=8)$

\begin{tabular}{lcc}
\hline \multicolumn{1}{c}{ Sample } & $\begin{array}{c}\text { Number of } \\
\text { osteoclasts } \pm \text { SD }\end{array}$ & $\begin{array}{c}\text { Bone Resorption, } \\
\text { percent of control } \pm \text { SD }\end{array}$ \\
\hline CONTROL & $235 \pm 29$ & $100 \pm 2,3$ \\
SA-16-DNA & $219 \pm 33$ & $41 \pm 3,3^{*}$ \\
SS-16-DNA & $241 \pm 19$ & $98 \pm 4,1$ \\
A-16-DNA & $233 \pm 25$ & $43 \pm 6,0^{\ddagger}$ \\
S-16-DNA & $257 \pm 12$ & $103 \pm 1,1$ \\
SA-60-DNA & $250 \pm 21$ & $32 \pm 2,1^{*}$ \\
SS-60-DNA & $223 \pm 29$ & $99 \pm 2,9$ \\
A-60-DNA & $199 \pm 36$ & $36 \pm 3,9^{*}$ \\
S-60-DNA & $239 \pm 23$ & $101 \pm 4,1$ \\
SA-CAII-DNA & $233 \pm 26$ & $30 \pm 5,4^{*}$ \\
SS-CAII-DNA & $212 \pm 29$ & $105 \pm 3,2$ \\
A-CAII-DNA & $244 \pm 30$ & $35 \pm 3,4^{*}$ \\
S-CAII-DNA & $230 \pm 23$ & $93 \pm 6,3$ \\
\hline
\end{tabular}

Osteoclasts were counted after toluidine blue staining as cells with at least three nuclei. Bone resorption was measured in relation to control by counting the number of resorption pits per osteoclast in each sample $\left({ }^{*} P<0.001 ;{ }^{\ddagger} P<0.01\right)$. 


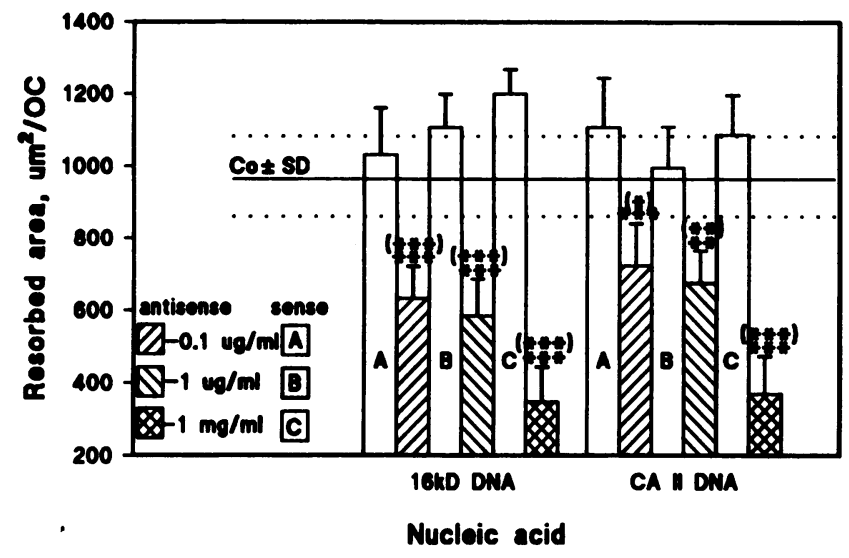

Figure 2. Resorbed bone area per osteoclast $(O C)$ after treatment with various concentrations of antisense or sense DNA $\pm \mathrm{SD}$. The $P$ values between sense and antisense, and control and antisense (in parenthesis) are shown as asterisks $\left({ }^{*} P<0.05 ;{ }^{* *} P<0.01 ;{ }^{* * *} P<0.001\right)$.

A-CA II-treated samples radioactivity after immunoprecipitation was $1294 \pm 189$ (A-CA II-RNA) and $2341 \pm 133$ (A-CA II-DNA).

For CRT-PCR, internal standard RNAs were produced for both CA II and the $16 \mathrm{kD}$ V-ATPase subunit, and this allowed us to examine the effects of the antisense molecules at the mRNA level of the corresponding protein (Fig. $4 \mathrm{~B}$ ). cRTPCR of RNA obtained from osteoclasts treated with sense oligos revealed the expected products for CA II and the $16 \mathrm{kD}$ V-ATPase subunit (Fig. $4 B$, lanes 1,3 , and 5). In contrast, there were no such CRT-PCR products detected when RNA was obtained from osteoclasts treated with antisense oligos (Fig. $4 B$, lanes 2, 4, and 7). This suggests that either transcription is inhibited, or the transcribed mRNA is rapidly degraded. In both cases, the amount of mRNA serving as template for translation is decreased.

The accumulation of $\mathrm{AO}$ was followed in osteoclasts treated with antisense molecules or specific enzyme inhibitors. $\mathrm{AO}$ is a weak base which accumulates into acidic compart- ments (32-34). When present at high concentrations, it forms complexes, resulting in a shift in fluorescence from green to red. A-16-RNA and A-CA II-RNA had opposite effects on intracellular acidification: A-16-RNA (Fig. $5 C$ ) increased AO accumulation into mononuclear cells and osteoclasts, but ACAII-RNA (Fig. $5 E$ ) decreased AO accumulation. The corresponding sense molecules (Fig. $5, D$ and $F$ ), or $1 \mathrm{mM}$ amiloride (Fig. $5 B$ ) had no effect on AO uptake compared to control (Fig. $5 A$ ).

In control cultures, bafilomycin $A_{1}$ inhibited accumulation of $\mathrm{AO}$ into intracellular vesicles partially at $5 \mathrm{nM}$, and totally at a $10 \mathrm{nM}$ concentration (Fig. 6, $A$ and $C$ ). At $1 \mathrm{nM}$ and $100 \mathrm{pM}$ concentrations, bafilomycin $A_{1}$ had no detectable inhibitory effect on intracellular acidification in the osteoclasts (Fig. 6, $E$ and $G$ ). However, when bafilomycin $\mathrm{A}_{1}$ was added to A-16RNA-treated cultures, weakly acidic vesicles appeared in the osteoclasts in the presence of $10 \mathrm{nM}$ bafilomycin (Fig. $6 \mathrm{~B}$ ). The amount of acidic vesicles increased when the concentration of bafilomycin $\mathrm{A}_{1}$ decreased (Fig. 6, $D, F$, and $H$ ).

Amiloride treatment inhibits acidification as indicated by decreased AO uptake (Fig. $7 A$ ). However, when A-16-RNA was added in the presence of amiloride (Fig. $7 \mathrm{~B}$ ), or with amiloride and bafilomycin $A_{1}$ (Fig. $7 C$ ), there is an increased acidification. This suggests that this bafilomycin-resistant, A-16-RNA-induced acidification mechanism is not amiloridesensitive either. These results strongly suggest that the acidification mechanism induced by A-16-RNA is not dependent on a conventional V-ATPase or a $\mathrm{Na}^{+} / \mathrm{H}^{+}$-exchanger.

We then studied endosomal acidification using VSV infection, and noticed that A-16-RNA inhibited it in cultured osteoclasts (Fig. 8, $A$ and $B$ ). Infection of enveloped viruses occurs, when endocytosed viruses fuse with acidic endocytic vesicles (35). Acidification of endosomes is brought about by V-ATPase, and VSV-infection should be inhibited if the proton pump is blocked by antisense molecules. Any of the senseRNAs did not inhibit VSV infection (Fig. 8, C-F). Bafilomy$\operatorname{cin} A_{1}$ is known to block endosomal acidification by inhibiting V-ATPases, and osteoclasts treated with $10 \mathrm{nM}$ bafilomycin $\mathrm{A}_{1}$ were not infected with VSV (Fig. 8, $G$ and $H$ ). When the bafi-
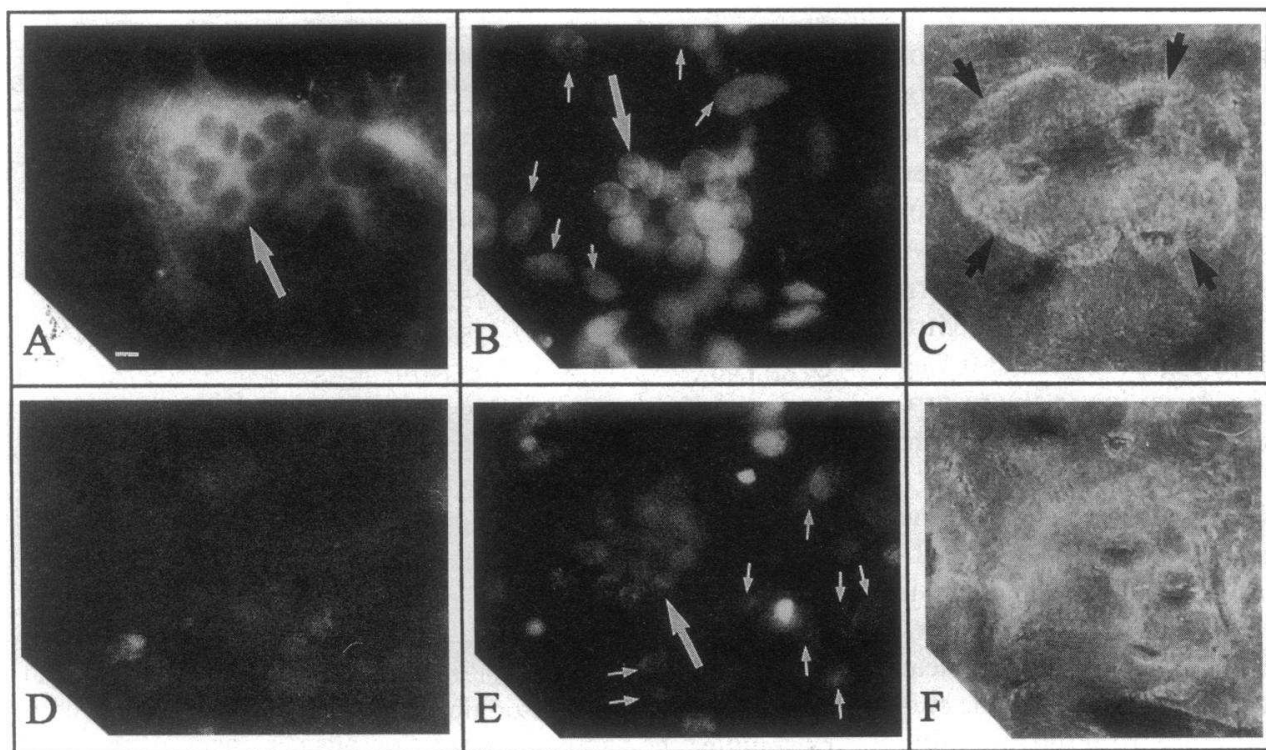

Figure 3. Immunostaining of CA II protein after sense $(A-C)$ or antisense $(D-F)$ CA II RNA treatment. Sense RNA-treated osteoclasts were positive for CA II $(A$, arrow $)$, and they were resorbing bone ( $C$, arrows point to the resorption lacuna). Antisense RNA-treated osteoclasts, which were negative for CA II $(D)$ were incapable of resorbing bone $(F)$. Osteoclast nuclei from the corresponding samples are marked with large arrows, and mononuclear cell nuclei with small arrows in $B$ and $E$. Bar, $10 \mu \mathrm{m}$. 

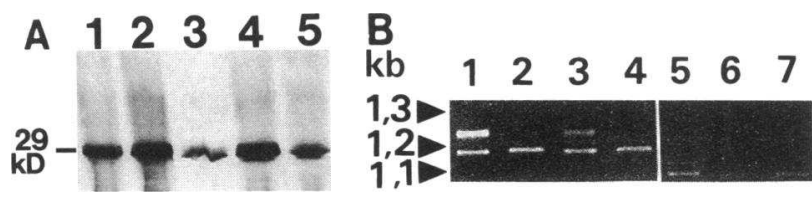

Figure 4. (A) Immunoprecipitation of metabolically labeled CA II protein after CA II sense or antisense treatment. Control (lane 1); S-CAII-RNA (lane 2); A-CAII-RNA (lane 3); S 7 CAII-DNA (lane 4); and A-CAII-DNA (lane 5) treated samples. (B) Agarose gel electrophoresis of cRT-PCR products from antisense RNA/DNA-treated osteoclasts. The upper band represents sample mRNA, and the lower band standard RNA lacking $40 \mathrm{nt}$ (V-ATPase) or $120 \mathrm{nt}$ (CA II). In S-CAII-RNA (lane 1), S-CAII-DNA (lane 3), and S-16-DNA (lane 5)-treated osteoclasts both sample mRNA and standard RNA bands can be seen. After A-CAII-RNA (lane 2), A-CAII-DNA (lane 4), and A-16-DNA (lane 7) treatment only standard RNA is visible, and the non-sense control (lane 6 ) is negative for both.

lomycin + A-16-RNA-treated osteoclasts were incubated with VSV, no infection was seen (Fig. 8, $I$ and $J$ ). This data also suggests that $A O$ accumulation in the presence of A-16-RNA is not dependent on endosomal V-ATPase.

\section{Discussion}

In this study we used the antisense technique to study the roles of V-ATPase and CA II in bone resorption, using two different in vitro bone resorption assays. The number of osteoclasts was the same in antisense-treated and control cultures, indicating that the antisense molecules in themselves were not toxic to
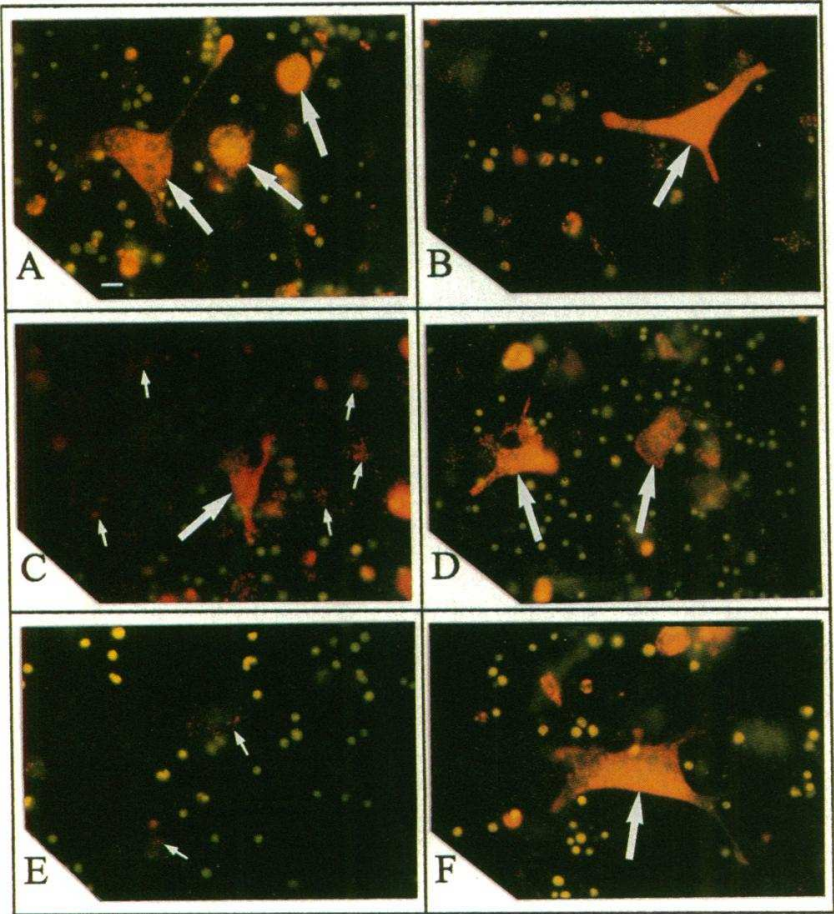

Figure 5. Intracellular accumulation of AO into osteoclasts treated with antisense or sense RNAs. Osteoclasts are marked with large arrows, and mononuclear cells with small arrows. Control $(A), 1 \mathrm{mM}$ amiloride $(B)$, A-16-RNA $(C)$, S-16-RNA $(D)$, A-CAII-RNA $(E)$, and S-CAII-RNA $(F)$ treatment. Bar, $10 \mu \mathrm{m}$. osteoclasts (Table II). In the resorption pit assay (Fig. $1 A$ ), the antisense molecules were able to decrease the total resorbed area. The effects of V-ATPase and CA II antisense molecules on bone resorption in calvaria cultures (Fig. $1 B$ ) were similar to the results obtained from the resorption pit assay.

Antisense DNA and RNA have been used to inhibit the translation of several proteins in vivo and in vitro. They have been used to transfect cells by using an antisense-bearing expression vector (36-38), and they have been added to cell cultures in vitro to inhibit cell attachment or expression of different proteins $(10,12,14,39-41)$. By these means, up to $95 \%$ inhibition of translation has been achieved in some experiments. According to our studies, antisense RNA molecules were more potent inhibitors of bone resorption than the shorter antisense DNA oligonucleotides. One reason for this could be that the length of the RNA nucleotide allows short mismatches without affecting the hybridization efficiency. Even if the added RNA was degraded rapidly in the cells, there would probably still be enough short fragments to inhibit translation. It has
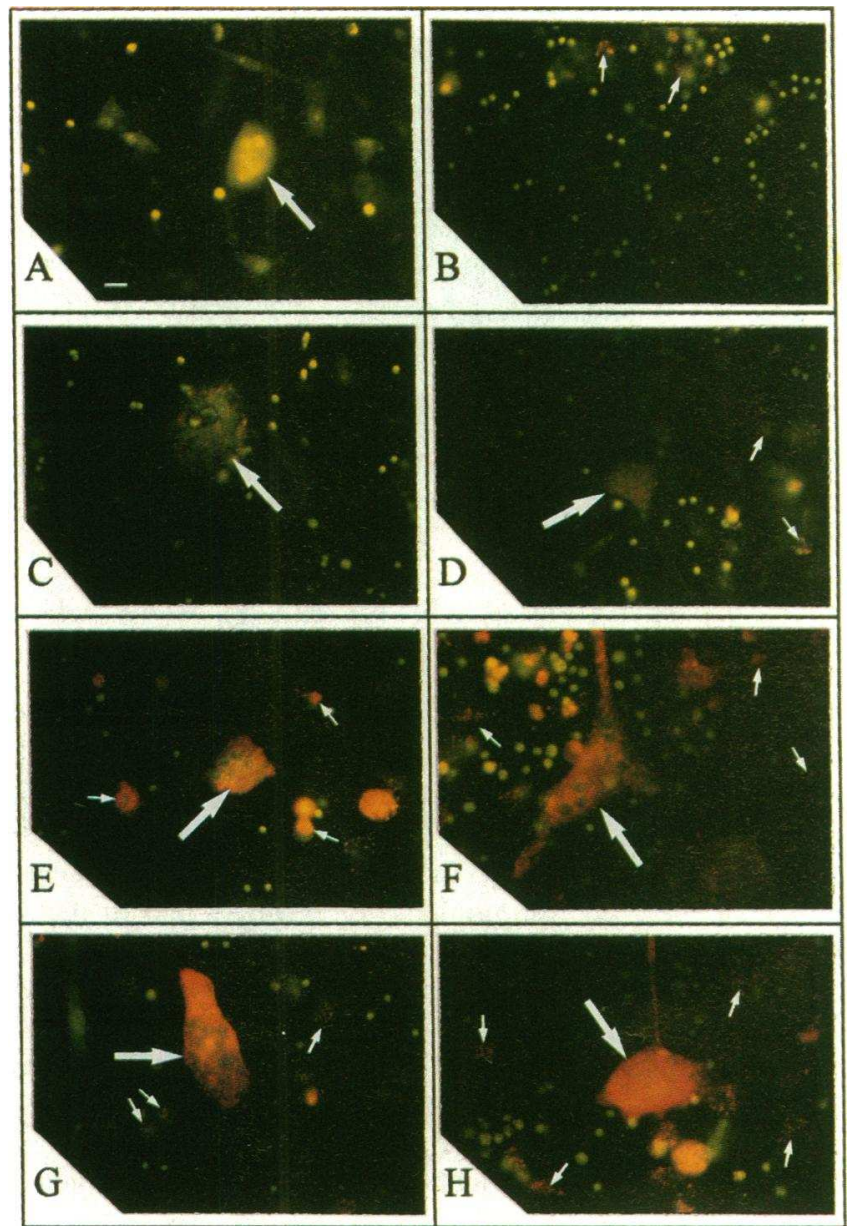

Figure 6. Intracellular accumulation of $\mathrm{AO}$ into osteoclasts treated with various concentrations of bafilomycin $\mathrm{A}_{1}$ alone $(A-D)$, or together with A-16-RNA $(E-H)$. Osteoclasts are marked with large arrows, and mononuclear cells with small arrows. $10 \mathrm{nM}$ bafilomycin $\mathrm{A}_{1}(A), 5 \mathrm{nM}$ baf. $\mathrm{A}_{1}(B), 1 \mathrm{nM}$ baf. $\mathrm{A}_{1}(C), 100$ pM baf. $\mathrm{A}_{1}(D), 10$ nM baf. $\mathrm{A}_{1}+$ A-16-RNA $(E), 5 \mathrm{nM}$ baf.A 1 + A-16-RNA $(F), 1 \mathrm{nM}$ baf. ${ }_{1}+$ A-16-RNA $(G)$ and 10 pM baf. $\mathrm{A}_{1}+\mathrm{A}-16-\mathrm{RNA}(H)$-treatment. Bar, $10 \mu \mathrm{m}$. 


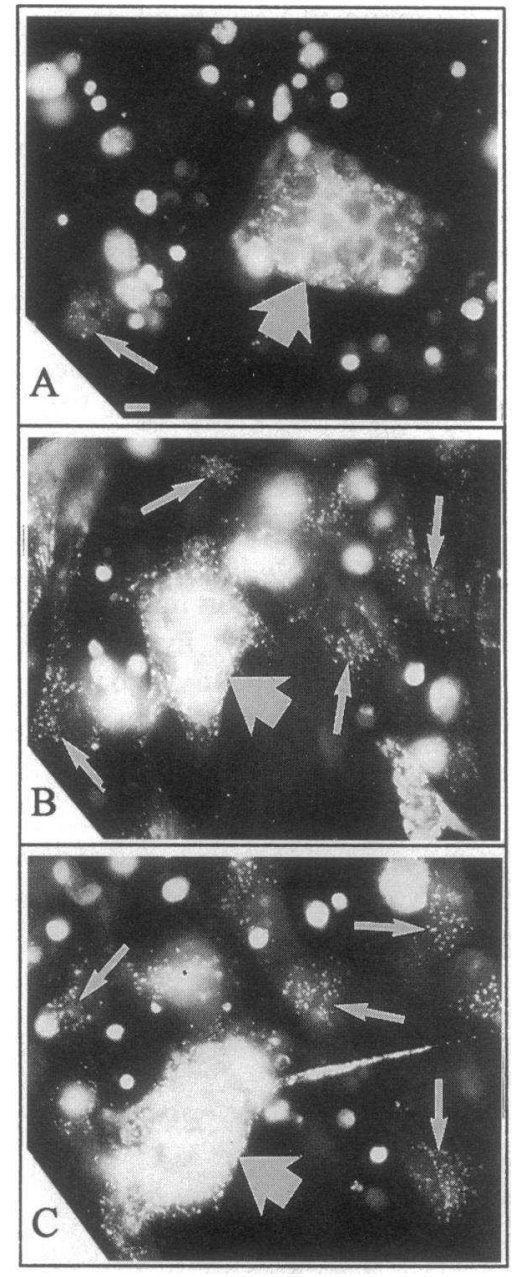

Figure 7. Intracellular accumulation of AO into osteoclasts treated with $1 \mathrm{mM}$ amiloride + S-16-RNA $(A), 1$ $\mathrm{mM}$ amiloride + A-16RNA $(B)$, or $1 \mathrm{mM}$ amiloride + A-16-RNA $+1 \mathrm{nM}$ bafilomycin $\mathrm{A}_{1}$ $(C)$. Acidic vesicles in mononuclear cells are marked with small arrows, and osteoclasts are marked with large arrows. Bar, $10 \mu \mathrm{m}$

also been suggested that long nucleic acid strands are transported to cells more efficiently than short oligonucleotides (9). There may thus also be a smaller concentration of the DNAoligo inside the osteoclasts to inhibit translation.

We found no great difference between the inhibitory effects of normal and backbone-modified S-DNA-oligos, indicating that degradation of the normal DNA-oligos in our system was not a big problem (Table II). In fact, the S-oligos had a smaller inhibitory effect on resorption. This could be due to their poorer capability of passing through the plasma membrane $(24,42)$. As little as $100 \mathrm{ng}$ of antisense $\mathrm{DNA} / \mathrm{ml}$ was enough to decrease bone resorption. When $>1 \mu \mathrm{g} / \mathrm{ml}$ was used, inhibition was not further increased in a linear manner. The results of previous studies have shown that high concentrations of antisense nucleotides may decrease the specificity of mRNA-antisense hybridization, and actually promote nonspecific degradation of mRNA (43).

On the basis of our immunofluorescence, immunoprecipitation and cRT-PCR results, the antisense-molecules against CA II inhibited the synthesis of CA II protein specifically. For the 16-kD V-ATPase subunit, we were only able to study the effect of the antisense molecules on mRNA levels by cRTPCR, due to lack of a suitable antiserum. Both CA II and the 16-kD V-ATPase antisense molecules decreased specific mRNA concentrations in the osteoclasts, so that they could not

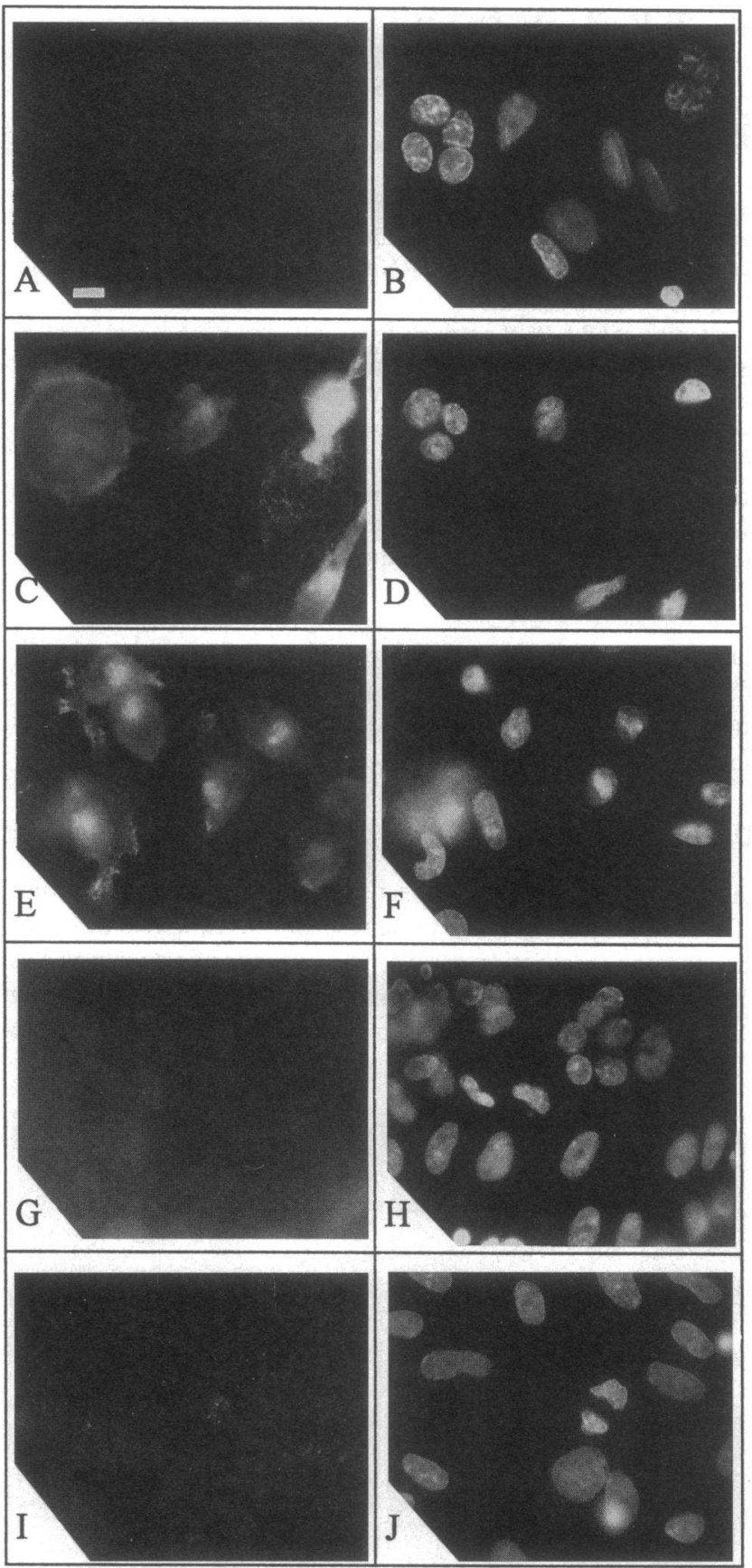

Figure 8. VSV G-protein staining after VSV-infection in cultures treated as follows: $(A)$ A-16-RNA, $(C)$ S-16-RNA, $(E)$ control, $(G)$ $10 \mathrm{nM}$ bafilomycin $\mathrm{A}_{1}$, and $(I) 10 \mathrm{nM}$ bafilomycin $\mathrm{A}_{1}+\mathrm{A}-16-\mathrm{RNA}$. Nuclei were visualized with Hoechst-staining in $B, D, F, H$ and $J$. Bar, $10 \mu \mathrm{m}$.

be detected after PCR (Fig. 4, lane 7). The CA II antisense molecules had no effect on overall protein synthesis, but they decreased translation of CA II protein, as determined by immunostaining, metabolic labelling and immunoprecipitation (Figs. 3 and $4, A$ and $B$, lanes 2 and 4 ).

Surprisingly, antisense RNA against the $16 \mathrm{kD}$ V-ATPase subunit did not inhibit intracellular acidification, as determined by AO-accumulation studies (Fig. $5 C$ ). Instead, use of this antisense RNA resulted in enormous accumulation of 
acidic vesicles inside the osteoclasts. Bafilomycin $A_{1}$, a specific V-ATPase inhibitor, decreased the accumulation of acidic vesicles into cultured osteoclasts (Fig. 6, $A-D$ ). However, in the presence of A-16-RNA, a population of bafilomycin-resistant acidic vesicles appeared in the osteoclasts (Fig. 6, E-H). Thus the acidification system of these vesicles differs from a classical vacuolar proton pump and $\mathrm{Na}^{+} / \mathrm{H}^{+}$-exchanger, because acid accumulation was not inhibited with bafilomycin $A_{1}$ or amiloride (Fig. 7).

To study the endosomal acidification mechanism in A-16RNA-treated osteoclasts, we used VSV infection as a test (Fig. 8 ). When endosomes are neutralized, VSV-infection is inhibited because viruses are not capable of fusing with endosomal membranes at neutral $\mathrm{pH}(35,44)$. This was confirmed first by blocking VSV infection with bafilomycin $A_{1}$ (Fig. $8 G$ ). A-16RNA treatment inhibited VSV infection, suggesting a specific effect on endosomal acidification (Fig. $8 A$ ). Sense RNA strands had no inhibitory effect on VSV-infection. These results suggest that the acidic vesicles which were formed in A-16-RNA-treated osteoclasts may not have been endosomes. However, we cannot exclude the possibility that A-16-RNA treatment may have disturbed vesicle transport in the osteoclasts, preventing internalization of the VSV.

We do not know the mechanism by which antisense-molecules enter the osteoclast. Because they are phagocytosing cells, the antisense-molecules may be taken into the cells by phagocytosis. Previously described receptor-mediated endocytosis may also be involved (9). However, it is most unlikely that the long RNA molecules, or even the 18-mer DNA-oligos, could enter the osteoclasts passively.

We have shown that osteoclastic bone resorption can be inhibited by antisense RNA- and DNA-molecules in vitro. These data confirm that antisense-molecules enter osteoclasts, and that they inhibit protein synthesis specifically. Our results also open a new, interesting possibility of using these antisense molecules in vivo. The use of small, osteoclast-specific antisense oligonucleotides against functionally important gene products, may give us a new potential therapeutic approach in bone resorption disorders.

\section{Acknowledgments}

We thank Dr. Nelson (Roche Institute, Nutley, NJ) and Dr. Curtis (Wistar Inst., Philadelphia, PA) for the cDNA clones, Dr. Metsikkö (University of Oulu, Finland) for the VSV, and Harri Palokangas and Petri Lehenkari for fruitful discussions. Allan Haimakainen, Eero Oja, and Minna Orreveteläinen are acknowledged for technical assistance.

This study was supported by the Sigrid Jusélius Foundation, Finnish Academy of Sciences, Magnus Ehrnrooth Foundation, and AB Astra Hässle, Sweden.

\section{References}

1. Lakkakorpi P. T., and H. K. Väänänen. 1991. Kinetics of the osteoclast cytoskeleton during the resorption cycle in vitro. J. Bone Miner. Res. 6:817-826.

2. Blair H. C., S. L. Teitelbaum, R. Ghiselli, and S. Gluck. 1989. Osteoclastic bone resorption by a polarized vacuolar proton pump. Science (Wash. DC). 245:855-857.

3. Väänänen H. K., E. K. Karhukorpi, K. Sundquist, B. Wallmark, I. Roininen, T. Hentunen, J. Tuukkanen, and P. Lakkakorpi. 1990. Evidence for the presence of a proton pump of the vacuolar $\mathrm{H}^{+}$-ATPase type in the ruffled borders of osteoclasts. J. Cell Biol. 111:1305-1311.

4. Gay G. V., and W. J. Mueller. 1974. Carbonic anhydrase and osteoclasts: localization by labeled inhibitor autoradiography. Science (Wash. DC). 183:432-434.

5. Väänänen H. K., and E.-K. Parvinen. 1983. High active isoenzyme of carbonic anhydrase in rat calvaria osteoclasts. Histochemistry. 78:481-485.

6. Sundquist K. T., M. Leppilampi, K., Järvelin, T. Kumpulainen, and H. K. Väänänen. 1987. Carbonic anhydrase isoenzymes in isolated rat peripheral monocytes, tissue macrophages, and osteoclasts. Bone (Elmsford). 8:33-38.

7. Laitala T., and K. Väänänen. 1993. Proton channel part of vacuolar $\mathrm{H}^{+}$-ATPase and carbonic anhydrase II expression is stimulated in resorbing osteoclasts. J. Bone Miner. Res. 8:119-126.

8. Minshull J., and T. Hunt. 1989. Polysomal mRNA ablation by oligodeoxynucleotides and RNase H. In: Antisense RNA and DNA. Cambridge series on biotechnology. St. John's College, Cambridge, England.

9. Loke S. L., C. A. Stein, X. H. Zhang, K. Mori, M. Nakanishi, C. Subasinghe, J. S. Cohen, and L. M. Neckers. 1989. Characterization of oligonucleotide transport into living cells. Proc. Natl. Acad. Sci. USA. 86:3474-3478.

10. Jaskulski D., J. K. DeRiel, W. E. Mercer, B. Calabretta, and R. Baserga 1988. Inhibition of cellular proliferation by antisense oligodeoxynucleotides to PCNA cyclin. Science (Wash. DC). 240:1544-1546.

11. Biro S., Y.-M. Fu, Z.-X. Yu, and S. E. Epstein. 1993. Inhibitory effects of antisense oligodeoxynucleotides targeting c-myc mRNA on smooth muscle cell proliferation and migration. Proc. Natl. Acad. Sci. USA. 90:645-658.

12. Sizeland A. M., and A. W. Burgess. 1992. Anti-sense transforming growth factor $\beta$ oligonucleotides inhibit autocrine stimulated proliferation of a colon carcinoma cell line. Mol. Biol. Cell. 3:1235-1243.

13. Holt J. T., R. L. Rendner, and A. W. Nienhuis. 1988. An oligomer complementary to c-myc mRNA inhibits proliferation of HL-60 promyelocytic cells and induces differentiation. Mol. Cell. Biol. 8:963-973.

14. Heikkilä R., G. Schwab, E. Wickstrom, S. L. Loke, D. H. Pluznik, R Watt, and L. M. Neckers. 1987. A c-myc antisense oligodeoxynucleotide inhibits entry into $S$ phase but not progress from $G_{0}$ to $G_{1}$. Nature (Lond.). 328:445-449.

15. Wang H., D. C. Watkins, and C. C. Malbon. 1992. Antisense oligodeoxynucleotides to $G_{S}$ protein $\gamma$-subunit sequence accelerate differentiation of fibroblasts to adipocytes. Nature (Lond.). 358:334-337.

16. Sundquist K., P. Lakkakorpi, B. Wallmark, and K. Väänänen. 1990. Inhibition of osteoclast proton transport by bafilomycin A, abolishes bone resorption. Biochem. Biophys. Res. Comm. 168:309-313.

17. Hall G. E., and A. D. Kenny. 1987. Role of carbonic anhydrase in bone resorption: effect of acetazolamide on basal and parathyroid hormone-induced bone metabolism. Calc. Tissue Int. 40:212-218.

18. Gogarten J. P., J. Fichmann, Y. Braun, L. Morgan, P. Styles, S. L. Taiz, K. DeLapp, and L. Taiz. 1992. The use of an antisense mRNA to inhibit the tonoplast $\mathrm{H}^{+}$-ATPase in carrot. Plant Cell. 4:851-864.

19. Nelson N. 1989. Structure, molecular genetics and evolution of vacuolar $\mathrm{H}^{+}$-ATPases. J. Bioenerg. Biomembr. 21:553-571.

20. Mandel M., Y. Moriyama, J. D. Hulmes, Y.-C. E. Pan, H. Nelson, and N. Nelson. 1988. cDNA sequence encoding the $16-\mathrm{kD}$ proteolipid of chromaffin granules implies gene duplication in the evolution of $\mathrm{H}^{+}$-ATPases. Proc. Natl. Acad. Sci. USA. 85:5521-5524.

21. Curtis P. J., E. Withers, D. Demuth, R. Watt, P. J. Venta, and R. E. Tashian. 1983. The nucleotide sequence and derived amino acid sequence of cDNA coding for mouse carbonic anhydrase II. Gene (Amst.). 25:325-332.

22. Sambrook J., E. F. Fritsch, and T. Maniatis. 1989. Molecular Cloning: A Laboratory Manual. Cold Spring Harbor Laboratory Press, Cold Spring Harbor, NY.

23. Ausubel F. M., R. Brent, R. E. Kingston, D. D. Moore, J. G. Seidman, J. A. Smith, and K. Struhl, editors. 1992. Current Protocols In Molecular Biology. John Wiley \& Sons, New York.

24. Hawkins J. W. 1989. Antisense molecular biology and s-oligos. In Antisense RNA and DNA. Cambridge series on biotechnology. St. John's College, Cambridge, England.

25. Lakkakorpi P. T., J. Tuukkanen, T. Hentunen, K. Järvelin, and K. Väänänen. 1989. Organization of osteoclast microfilaments during the attachment to bone surface in vitro. J. Bone Miner. Res. 4:817-825.

26. Ferre F. 1992. Quantitative or semiquantitative PCR: reality versus myth. PCR Methods and Applications. 2:1-9.

27. Pallen M. J., L. H. Puckley, and B. W. Wren. 1992. A rapid, simple method for detecting PCR failure. PCR Methods and Applications. 2:91-92.

28. Goding J. W. 1986. Monoclonal Antibodies: Principles and Practice. Academic Press Limited, London, England.

29. Metsikkő K., T. Hentunen, and K. Väänänen. 1992. Local expression and endocytosis of viral glycoproteins in multinucleated muscle cells. J. Cell Biol. 117:987-995.

30. Reynolds J. J. 1976. Organ cultures of bone: studies on the physiology and pathology of resorption. In Organ Culture in Biomedical Research. M. Bull and M. A. Monnickendam, editors. Cambridge University Press, Cambridge. 355366.

31. Lerner U. H. 1987. Modifications of the mouse calvarial technique im- 
prove the responsiveness to stimulators of bone resorption. J. Bone Miner. Res. 2:375-383.

32. Matteoni R., and T. E. Kreis. 1987. Translocation and clustering of endosomes and lysosomes depends on microtubules. J. Cell Biol. 105:1253-1265.

33. Cain C. C., and R. F. Murphy. 1988. A chloroquine-resistant Swiss 3T3 cell line with a defect in late endocytic acidification. J. Cell Biol. 106:269-277.

34. Palmgren M. G. 1991. Acridine orange as a probe for measuring $\mathrm{pH}$ gradients across membranes: mechanism and limitations. Anal. Biochem. 192:316-321.

35. Marsh M. 1984. The entry of enveloped viruses into cells by endocytosis. Biochem. J. 218:1-10.

36. Steele C., P. G. Sacks, K. Adler-Storthz, and E. J. Shillitoe. 1992. Effect on cancer cells of plasmids that express antisense RNA of human papillomavirus type 18. Cancer Res. 52:4706-4711.

37. Barabino S. M. L., B. S. Sproat, and A. I. Lamond. 1992. Antisense probes targeted to an internal domain in U2 snRNP specifically inhibit the second step of pre-mRNA splicing. Nucleic. Acids Res. 20:4457-4464.

38. Wu, G. Y., and C. H. Wu. 1992. Specific inhibition of hepatitis B viral gene expression in vitro by targeted antisense oligonucleotides. J. Biol. Chem. 267:12436-12439.
39. Lallier T., and M. Bronner-Fraser. 1993. Inhibition of neural crest cell attachment by integrin antisense oligonucleotides. Science (Wash. DC). 259:692-695.

40. Pepin M.-C., F. Pothier, and N. Barden. 1992. Impaired type II glucocorticoid receptor function in mice bearing antisense RNA transgene. Nature (Lond.) 355:725-728.

41. Simons M., E. R. Edelman, J.-L. DeKeyser, R. Langer, and R. D. Rosenberg. 1992. Antisense c-myb oligonucleotides inhibit intimal arterial smooth muscle cell accumulation in vivo. Nature (Lond.). 359:67-70.

42. Larrouy B., C. Blonski, C. Boiziau, M. Stuer, S. Moreau, D. Shire, and J. -J. Toulme. 1992. RNase H-mediated inhibition of translation by antisense oligodeoxyribonucleotides: use of backbone modification to improve specificity. Gene (Amst.). 121:189-194.

43. Cohen J. S. 1989. Topics in Molecular and Structural Biology. The Macmillan Press, London, England.

44. Eidelman O., R. Schlegel, T. S. Tralka, and R. Blumenthal. 1984. pH-dependent fusion induced by vesicular stomatitis virus glycoprotein reconstituted into phospholipid vesicles. J. Biol. Chem. 259:4622-4628. 